\title{
HYPERSPECTRAL REMOTE SENSING FOR MINERAL MAPPING: A CASE-STUDY AT ALTO PARAÍSO DE GOÍAS, CENTRAL BRAZIL
}

\author{
ALVARO PENTEADO CRÓSTA ${ }^{1}$ AND CARLOS ROBERTO DE SOUZA FILHO ${ }^{1}$
}

\begin{abstract}
After many decades of successful advances in applying multispectral remote sensing to the study of the Earth's characteristics and processes, a new data acquisition technology is emerging: hyperspectral remote sensing. This technology comprises the remote measurement of specific chemical and physical properties of surface materials through imaging spectroscopy. In this paper we examine the capability of hyperspectral remote sensing data acquired by the AVIRIS airborne instrument, over an area near Alto Paraíso de Goías. This area was chosen as a function of data availability, and not due to its geological characteristics. It comprises Proterozoic metasediments with little mineralogical variations and, although it does not represent an ideal site for the use of hyperspectral data, some interesting results were found in terms of mineral identification in portions of the image where enough ground exposure existed. Mineral assemblages, comprising mixtures of primary and secondary minerals, the latter related to weathering processes, were identified in the imagery, based solely on spectral signatures of pixels. These mixtures comprised mainly hematite, goethite, halloysite, kaolinite and Na-montmorillonite. Results were confirmed by laboratory reflectance measurements and scanning electron microscope (SEM) analysis of soil samples, demonstrating the usefulness of AVIRIS data and the efficiency of the methods employed for remote mineral mapping. However, vegetation showed to represent a constraint for mineral mapping, since it is likely to conceal spectral information due to rocks and minerals.
\end{abstract}

Keywords: hyperspectral remote sensing, mineral mapping, reflectance spectroscopy, AVIRIS

INTRODUCTION Advances in sensor technology and the increasing demand by the user's community for higher resolution data are leading to a swift development of hyperspectral remote sensing. A number of airborne hyperspectral sensors have been employed in recent years, mostly to test the technology and to demonstrate its benefits, providing the necessary research background to support future operational applications. Still, existing airborne sensors have acquired data over geographically restricted areas of the Earth. Spaceborne hyperspectral sensors are planned to be launched in the near future, providing world-wide coverage.

Regional geological mapping and mineral exploration are among the main applications that will benefit from hyperspectral technology. Minerals and rocks exhibit diagnostic spectral features throughout the electromagnetic spectrum that allow their chemical composition and relative abundance to be mapped. Narrow-band sensors operating from airborne and spaceborne platforms, with sufficient resolution to detect these features, can be used to remotely discriminate and identify such natural materials.

Most of the studies using hyperspectral data for geologic applications have so far addressed areas of arid to semi-arid climates. Under these climates, the vegetation cover and soils are scant and, consequently, geologic features have their original chemical composition better preserved and exposed than in tropical regions. In the tropics, geologic studies based on high-resolution remote sensing are extremely limited, due to the lack of data and also the lack of research about the spectral properties of weathered geologic materials.

In Brazil, available assessments of high spectral resolution data are mostly based on Geoscan 24-band MK-II multispectral scanner (Prado and Crosta 1997). These results showed a worthy potential for geologic applications of such data, constrained by weathering effects and the limited exposure of materials at the surface.

Hyperspectral remote sensing data were acquired for the first time in South America in 1995, over some areas of Brazil, using NASA's Advanced Visible and Near-Infrared Imaging Spectrometer (AVIRIS). The survey was part of SCAR-B (Smoke, Cloud and Radiation-Brazil), a joint scientific mission between NASA, the Brazilian Space Agency (AEB) and the Brazilian National Institute for Space Research (INPE) The unique dataset collected by this mission over Brazil represents the first hyperspectral data ever acquired over a tropical region. Characteristics of the AVIRIS sensor are shown in Table 1.

In this paper, we examine the potential of AVIRIS data for geologic mapping in a tropical region, considering the constraints imposed by weathering, soil and vegetation coverage. The area chosen for such evaluation, a portion of an AVIRIS flight line over the region of Alto Paraíso de Goías collected for calibration purposes on a cloud-free day, does not contain genuine mineral exploration targets (e.g., hydrothermal alteration minerals), since SCAR-B data requests were restricted to the mission's specific objectives (smoke and cloud detection). This image was used for assessing the ability of AVIRIS data to map different mineral assemblages that occur in association with metasedimentary units of a poorly geologically known region.
The results presented here refer to image processing procedures for extracting the spectral information related to minerals from the AVIRIS hyperspectral data cube and also to the validation of these results using laboratory data.

PHYSIOGRAPHY AND GEOLOGY OF ALTO PARAÍSO DE GOIAS The region of Alto Paraíso de Goías (APG) is located in Goías State, between the geographic coordinates $47^{\circ} 30^{\prime}-47^{\circ} 40^{\prime} \mathrm{W}$ and $14^{\circ} 00^{\prime}-14^{\circ} 15^{\prime} \mathrm{S}$. The area had relatively sparse vegetation at the time of imagery acquisition (August 1995), which coincided with the peak of the dry season. The dominant vegetation type is the "cerrado" (savanna-type vegetation). The presence of non-photosynthetic active (dry) vegetation (grass, shrubs and short trees) at this time of the year contributes to lower considerably the amount of electromagnetic energy reflected from underlying bedrock and soils.

APG is located in the outer portion of the Brasilia Fold Belt, a major tectonic unit formed lately during the Brasiliano/Pan African orogeny $(\sim 600 \mathrm{Ma})$. The region contains a variety of metasediments folded and sheared under ductile deformation.

The lithostratigraphic units that occur in this region belong to the Araf Group (Meso-Proterozoic) and to the Paranoá Group (Meso to Neo-Proterozoic). The Araf Group is represented in this region by the Arraias Formation, a thick sequence of coarse quartzites intercalated by metasiltites and phyllites. These rocks form a remarkable physiographic unit in the northern/north-eastern portion of the area (Fig. 1), called Chapada dos Veadeiros. The Paranoá Group, in the southern portion of the area, comprises a sequence of meta-pelites, metasiltites and quartzites.

HYPERSPECTRAL DATA PROCESSING Processing hyperspectral data requires different approaches in comparison to multispectral data. The idea behind hyperspectral data is to identify the composition of superficial materials based on their spectral signature in the 0.400 to $2.500 \mu \mathrm{m}$ wavelength range. For this purpose, some sort of comparison between pixel spectral signatures (unknown) and spectral signatures of reference materials (known) needs to be made, in order to establish quantitatively how similar a pixel is compared to the reference materials.

The first step in hyperspectral data processing consists in removing interference due to atmospheric components (gases such as $\mathrm{H}_{2} \mathrm{O}, \mathrm{CO}_{2}$, $\mathrm{O}_{3}$, etc., plus particulates, such as smoke and dust), and leaving only the spectral response of the surface materials. The data needs then to be converted from radiance units to reflectance, for direct comparison between pixel spectra and reference spectra. The second step involves the application of classification techniques for mapping surface materials. These techniques compare image spectra on a individual (pixel) basis to a spectral reference library.

AVIRIS data are provided by the Jet Propulsion Laboratory in radiance units, after being spectrally, radiometrically and geometrically calibrated using laboratory and in-flight procedures described by Green et al. (1996). The conversion to reflectance was done with the 


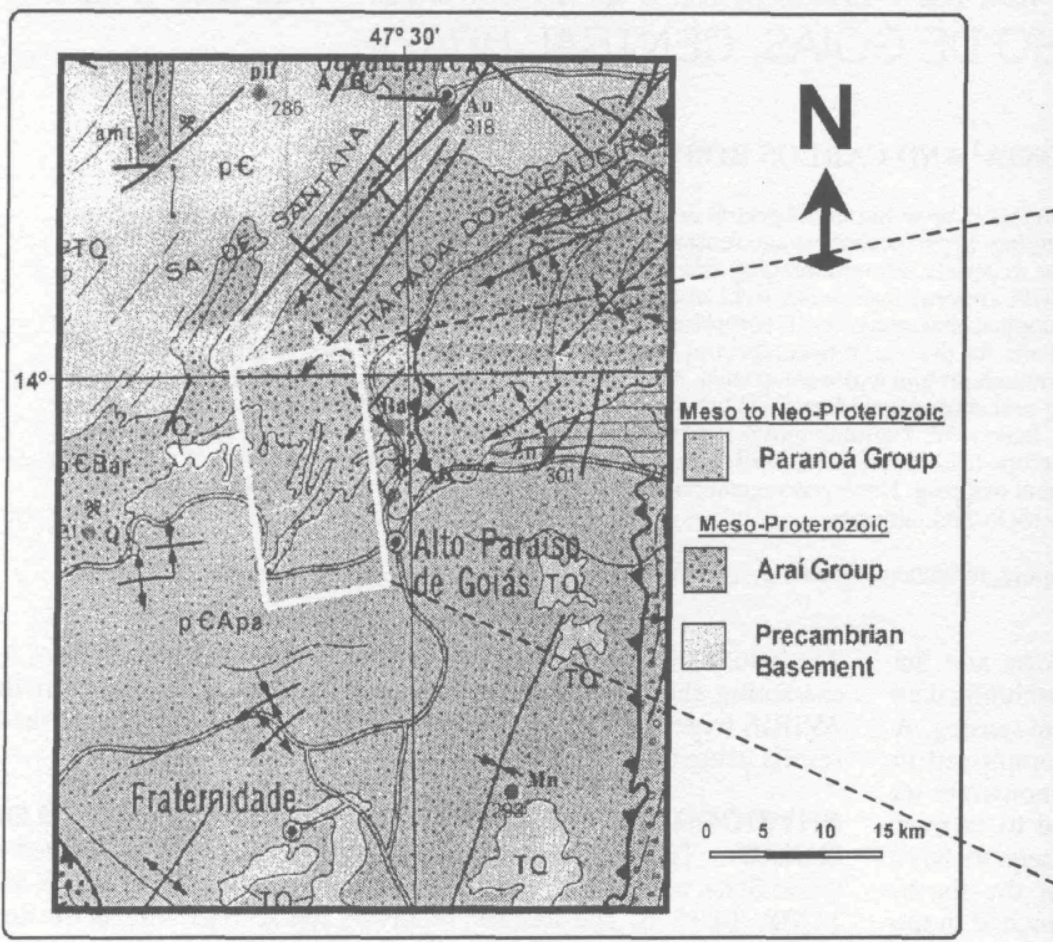

\section{AVIRIS Hyperspectral Data Cube}

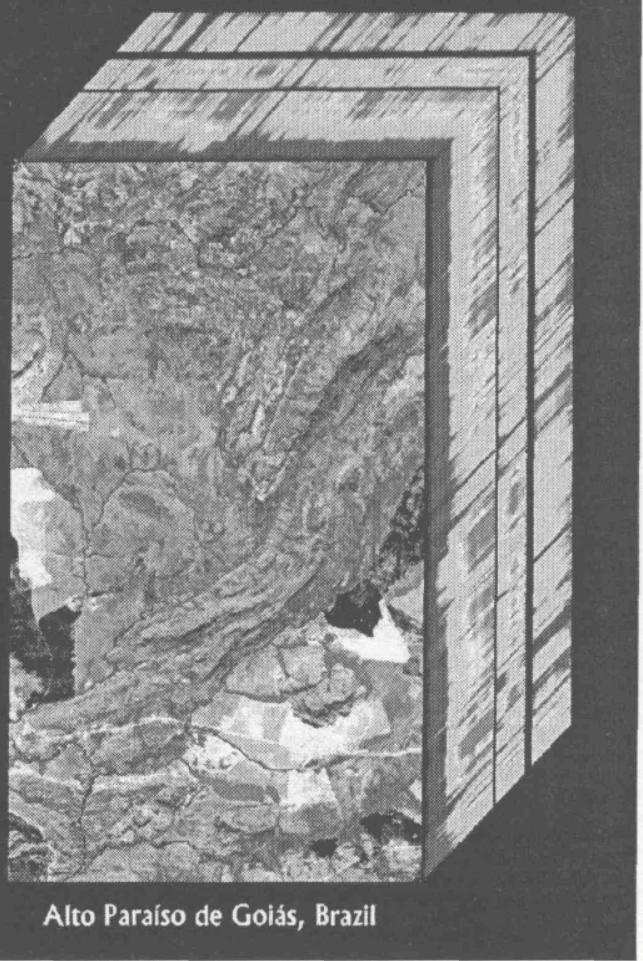

Figure 1-Regional geological map of Alto Paraiso de Goías (DNPM 1976). Note the location of the AVIRIS scene within the map. The AVIRIS hyperspectral data cube is on the right, with one of the 224 spectral bands (band 58, $0.903 / \mu \mathrm{m}$ ) shown on top. Variations in grey levels on the upper and right side of the cube represent spectral signatures of pixels located along these edges, ranging from 0.400 to $2.500 \mu \mathrm{m}$. The two black strips along this wavelength range are the portions of the electromagnetic spectrum where the atmospheric water absorbs all the energy.

\section{Table J-AVIRIS sensor and data characteristics}

\begin{tabular}{|l|l|}
\hline Sensor type & Whiskbroom scanner \\
\hline Dispersion & Four grating spectrometers (A, B, C, D) \\
\hline Number of bands & 224 \\
\hline Detectors & $224(32,64,64,64) \mathrm{Si}$ and InSb \\
\hline Radiometric resolution & 12 bits \\
\hline Spectral range & Spectrometer A: 0.400 to $0.700 \mu \mathrm{m}$ - Visible \\
& $\begin{array}{l}\text { Spectrometer B: } 0.700 \text { to } 1.300 \mu \mathrm{m}-\text { Near infrared } \\
\text { Spectrometer C: } 1.300 \text { to } 1.900 \mu \mathrm{m}-\text { Shortwave infrared } \\
\text { Spectrometer D: } 1.900 \text { to } 2.500 \mu \mathrm{m}-\text { Shortwave infrared }\end{array}$ \\
\hline Spectral resolution (FWHM) & $10 \mathrm{~nm}$ \\
\hline Calibration accuracy & $<1 \mathrm{~nm}$ \\
\hline Field of view & 30 degrees - 11 km \\
\hline Spatial resolution (IFOV) at 20 km altitude & $20 \mathrm{~m}-1.0 \mathrm{mrad}$ \\
\hline Platform & NASA's ER-2 \\
\hline Date of data acquisition (Alto Paraíso de Goiás) & 16 August $1995-\sim 15: 35$ local time \\
\hline
\end{tabular}

use of a radiative transfer model (MODTRAN) combined with laboratory and in-flight calibration data (Green et al. 1993). This method allows to derive "apparent" reflectance and provides sufficiently good precision for mineral mapping (Boardman and Huntington 1996, Crosta et al. 1998).

The Tricorder classification technique, developed at USGS's Spectroscopy Laboratory (Clark and Swayze 1995), was used for establishing the spectral similarity between pixel spectra and reference spectra. This allowed us to identify and map the distribution of minerals in the AVIRIS image of APG. Tricorder is an expert system that compares the absorption features present in each pixel of AVIRIS data to the characteristic absorption features of minerals from a spectral library. We used the USGS Digital Spectral Library which contains more than 300 materials, including minerals, mineral mixtures, vegetation, water, snow and man-made materials (Clark et al 1993). Tricorder compares the wavelength position and shape of absorption features in the AVIRIS data with those in each selected reference sample of the library. A modified least-squares fitting algorithm is used to assess the closeness of the match.

The AVIRIS data cube was processed through the Tricorder algorithm in two steps. In the first, we used 68 bands in the 0.440 to 1.070 urn spectral range (visible and near infrared portion of the electromagnetic spectrum) and analyzed them for seven reference spectra of common $\mathrm{Fe}^{2+}$ and $\mathrm{Fe}^{3+}$-bearing minerals, which show diagnostic spectral features mainly in this spectral range. In the second step we employed 38 bands in the 2.040 to $2.410 \mu \mathrm{m}$ spectral range 
(shortwave infrared) and analyzed them for nine hydroxyl-bearing minerals and carbonates. The minerals used for comparison were chosen from the USGS Spectral Digital Library as a function of the expected mineralogy for the area.

MINERAL MAPPING RESULTS ON THE APG AVIRIS SCENE The results of mineral mapping from the AVIRIS scene of APG are presented in this section, focussing in a small portion of the scene where sufficient spectral response due to minerals was registered by the sensor. Most of the scene pixels do not exhibit mineral spectral features but features akin to dry and green vegetation, which evidently were not classified as mineral assemblages by Tricorder.

The AVIRIS scene of APG was acquired during the peak of the dry season and therefore green vegetation was limited to riparian forests along the main drainage channels. But even non-photosynthetic active vegetation, which occupied most of the area at the time of imagery acquisition, has a significant spectral signature, which masks mineral signatures from rock and soil, as shown by Galvão et al. (1999).

Fig. 2.A shows a geo-referenced AVIRIS image, with the location of the portion of the scene where most pixels with mineral spectral signatures allowed the classification to be performed (white square). Within this portion, the majority of the classified pixels are located in two round-shaped clusters and along the unpaved road that cuts the area in the east-west direction, going from APG to the locality of Sao Jorge.

Tricorder results for AVIRIS bands located in the visible and nearinfrared portions of the electromagnetic spectrum include the identification of hematite and goethite (Fig. 2.B). Hematite was mapped mostly along the unpaved road and on the eastern side of the cluster on the right-hand side of the area. Two types of goethite from the USGS Digital Spectral Library were identified by Tricorder: type1 is a fine-grain variety and was mapped by Tricorder on both clusters, whereas type- 2 is a coarser variety and was identified only on the northeastern portion of the cluster on the left-hand side of the area.

Shortwave infrared AVIRIS bands produced a mineral distribution map comprising kaolinite, halloysite and a mixture of pyrophillite+kaolinite (Fig. 2.C). The cluster located in the left-hand side of the area shows what looks like a zonation of these three minerals, with halloysite occupying the center of the cluster, surrounded by kaolinite and then by an outer zone comprising pyrophillite+kaolinite. The results for the cluster on the right-hand side show a different distribution, comprising mostly kaolinite, with two areas of halloysite on the southwestern and eastern portions. The unpaved road exhibits an area of pyrophillite+kaolinite just south of the cluster on the right-hand side.

\section{VALIDATION OF AVIRIS IMAGERY CLASSIFICATION}

The results achieved in the previous sections were verified through field-checking and laboratory analysis, comprising scanning electron microscope (SEM) and reflectance spectroscopy. The data derived from this ground-truth were used for comparison with the AVIRIS imagery classification results.

Field Checking The round-shaped clusters in the image (Figs. 2A and $2 \mathrm{~B}$ ) correspond in the field to small hills where weathered metapelites from the Arraias Formation crop out, with no significant vegetation on top. Surface material is restricted to soils and colluvium. The base of the hill on the left-hand side of the area is surrounded almost entirely by Fe-rich laterite, where coarse ferriferous concretions are ubiquitous. The top of this hill is marked by a clay and quartz-rich soil mixed with sparse, fine-grained ferriferous concretions. The other hill, on the right-hand side of the area, typically lacks in coarse ferriferous concretions. Its top portion is covered by soils with plenty of quartz and fragments of quartz veins supported by a matrix rich in reddish clays, which may dominate the downhill surface. The eastern portion of this hill is composed of a colluvium involving a mix of clays and Fe-rich materials. A total of 11 samples of soils were collected throughout both sites for laboratory investigation.

Scanning Electron Microscope (SEM) Analysis Chemical composition of minerals present in soil samples was quickly yielded through SEM analysis, using a LEO 430i equipment. SEM results of all samples basically show two classes of minerals. One class displays high counts of $\mathrm{Fe}, \mathrm{O}, \mathrm{Ti}$ and low counts of $\mathrm{Si}$ and $\mathrm{Al}$. The other class reveals high counts of $\mathrm{Al}, \mathrm{Si}, \mathrm{O}$ and $\mathrm{K}$ and very low counts of $\mathrm{Fe}$. This concurs with the presence of goethite/hematite and minerals of the kaolinite group.
Reflectance Spectroscopy Reflectance measurements were performed using a FieldSpec FR $(0.300-2.500 \mu \mathrm{m})$ spectroradiometer. The spectra for all samples were classified using the SpectrometerIndependent Mineral Identification Software (SIMIS). Twenty-two minerals and mixture of minerals, expected to occur in the studied samples, were selected from the USGS Spectral Library for mineral

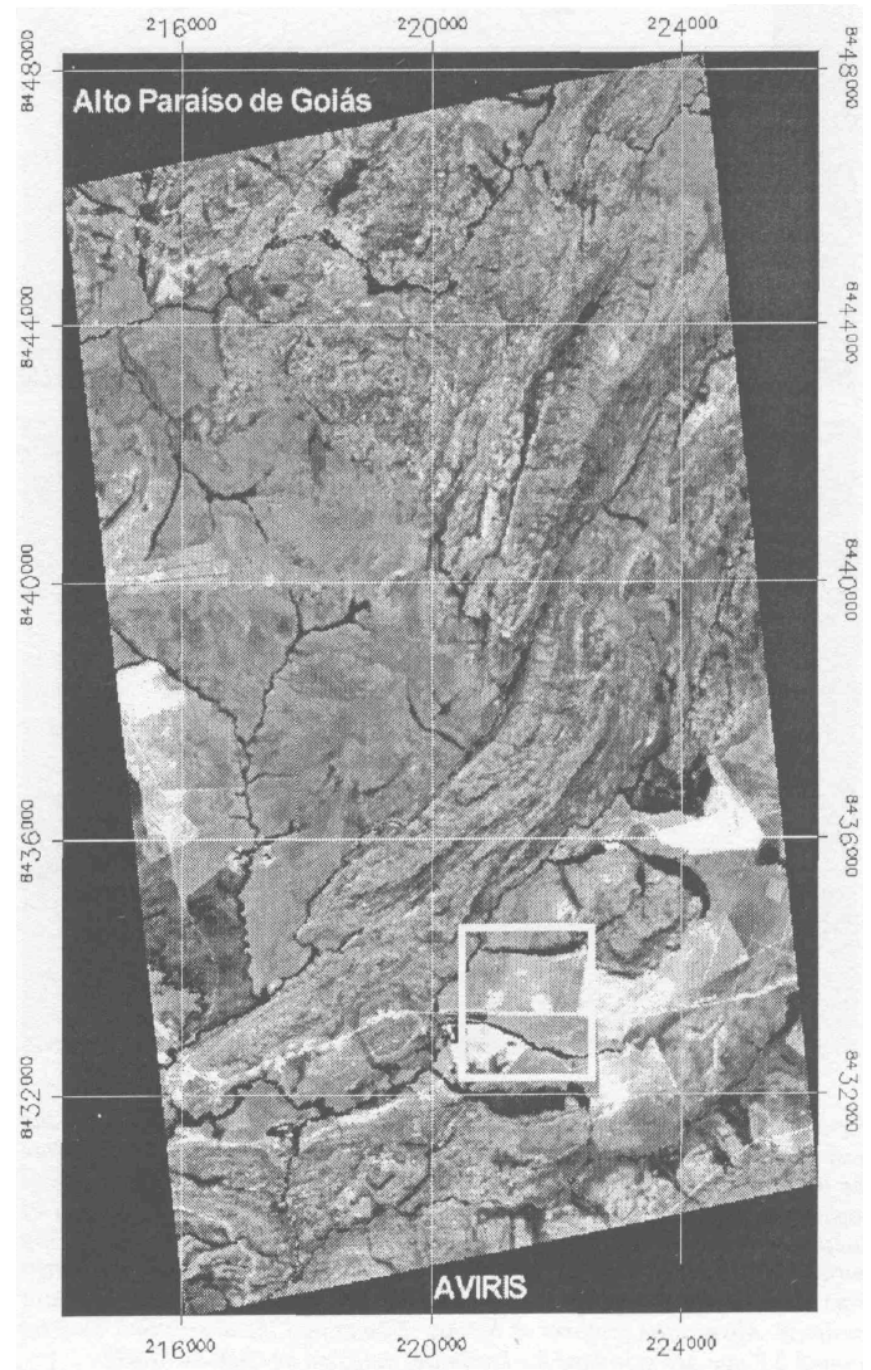

(A)

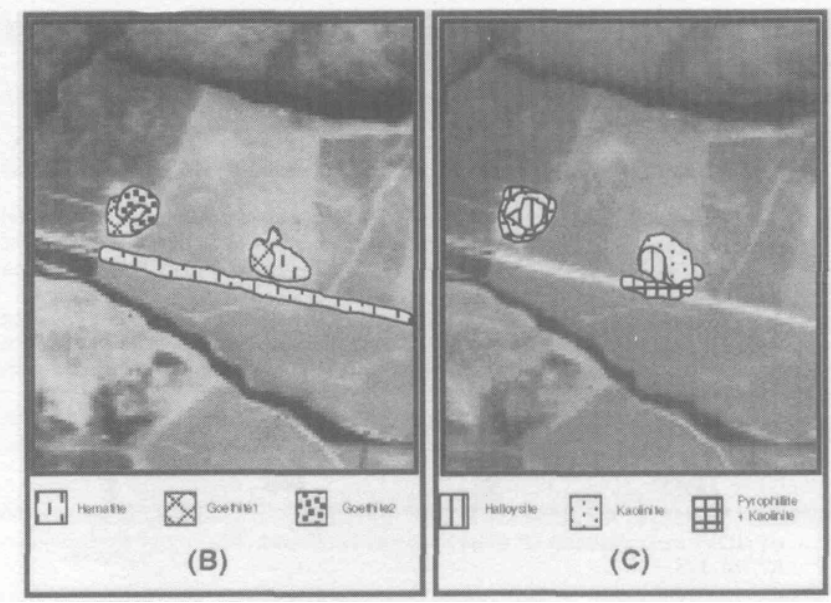

Figure 2-(A) Geo-referenced AVIRIS scene, showing the area (white square) for which the Tricorder mineral mapping results are presented in $(B)$ and $(C)$; (B) Tricorder results for the VNIR bands - goethite type-1 is a fine-grain variety, whereas goethite type-2 is a coarse-grain variety; (C) Tricorder results for the SWIR bands. 

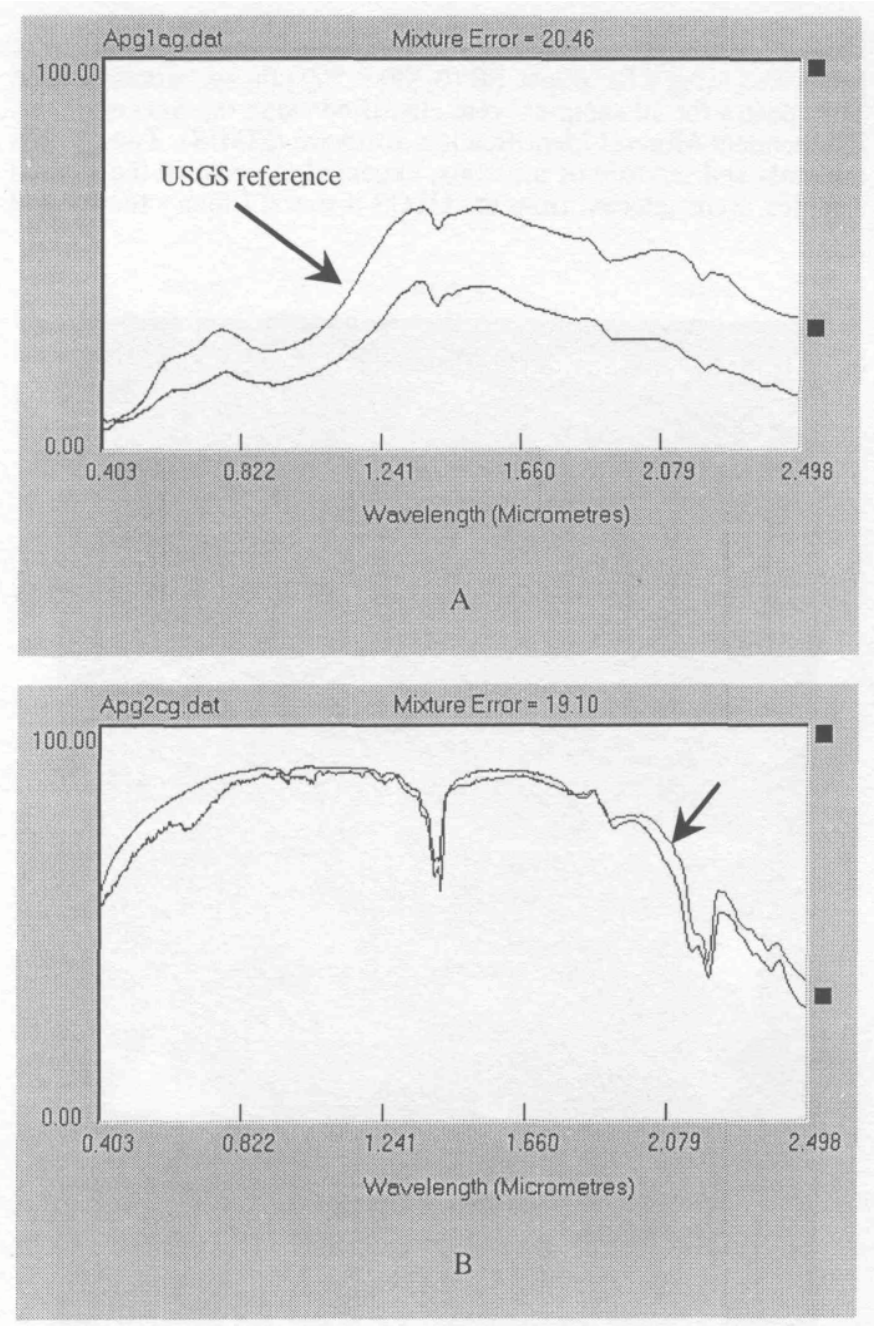

Figure 3-(A) Spectral reflectance curve for ferriferous concretions found at the base of the hill to the left of the zoomed AVIRIS image (Figs. 2.A and B). Note the match between the USGS spectral curve for goethite and the measured sample. Absorption features at $0,5 \mathrm{~mm}, 0.65 \mathrm{~mm}$ and $0,9 \mathrm{~mm}$ are typical of goethite, as classified by SIMIS. (B) Spectral reflectance curve for the top portion of the hill to right of the zoomed AVIRIS image. The curve stemmed from this sample is almost identical to that of the USGS library for pure kaolinite. Absorption features at 1,4mm, 1,9mm and the absorption doublet around 2,2 mm are standard for kaolinite, detected as such by SIMIS. classification. There are two analysis procedures available in SIMIS: feature position and curve shape identification. Feature position uses information on the positions and depths of spectral features to determine possible end-members for an unmixing solution. Curve shape identification uses normalized spectra in a cross-correlation algorithm to determine possible end-members. An additional program, statistical unmixing, carries out a two pass unmixing solution. In the first case the negative proportions are eliminated and the remaining endmembers are passed through an unmixing algorithm with the reduced library to produce the final proportions estimates. In most cases this reduced the 22 mineral library to $2-4$ end-members.

The spectral curves and SIMIS results showed a reasonable match with field and SEM data. Figs. 3A and 3B display the spectra of samples collected at the bottom of the hill to the left (where ferriferous concretions are described) and at the top of the hill to the right (where argillaceous soils were found) of the area. Fig. 3A reveals a typical goethite spectrum (absorption features at $0,5 \mathrm{~mm}, 0,65 \mathrm{~mm}$ and $0,9 \mathrm{~mm}$ ), and it was correctly classified by SIMIS as such. Fig. 3.B portrays a spectrum that is characteristic of kaolinite (absorption features at $1.4 \mathrm{~mm}, 1,9 \mathrm{~mm}$, and a doublet around $2,2 \mathrm{~mm}$ ), also perfectly identified by SIMIS.

DISCUSSION AND CONCLUSIONS Field data combined with SEM and reflectance spectroscopy analysis shows that the APG AVIRIS imagery classification results are outstanding. The bulk of mineral assemblages identified by Tricorder on AVIRIS data were later confirmed by field features (e.g., presence of coarse ferriferous concretions at the base of the hill to the left of the image and position of soils rich in clays). SEM analysis also separated two classes of minerals that are dominant in the soils collected in the field - viz. goethite and kaolinite. The spectral signature for the studied samples showed an excellent agreement with Tricorder results, clearly distinguishing between zones rich in Fe-hydroxides and minerals of the kaolinite group. These results demonstrate the usefulness of AVIRIS data and the efficiency of the methods employed here for remote mineral mapping.

The data and methods addressed here are restricted by features typical of tropical environments. Pixels classified in the imagery as containing mineral assemblages lack in vegetation, or comprise a minimum of vegetation cover. This illustrates one of the main limitations of hyperspectral remote sensing for mineral mapping in non-arid regions, where vegetation is likely to conceal spectral information due to soil and rocks. In this sense, the presence of nonphotosynthetic (dry) vegetation showed to be a major obstacle for mineral identification in the APG terrains.

Acknowledgements The authors acknowledge the support of Fundação de Amparo a Pesquisa no Estado de Sao Paulo (FAPESP), through grants 96/08282-8, 96/11139-2 and 95/6401-7. A. P. Crosta and C. R. de Souza Filho thank Conselho Nacional de Desenvolvimento Cientffico e Tecnologico (CNPq) for their research grants 320229/84-0 and 301227/94-2, respectively.

\section{References}

Boardman J.W. \& Huntington, J.F. 1996. Mineral mapping with 1995 AVIRIS data. In: Sixth Annual JPL Airborne Earth Science Workshop, Pasadena, JPL Publ. 96-4,1:9-11.

Clark R.N., Swayze G.A., Gallagher A.J., King T.V.V., Calvin W.M. 1993. The USGS Digital Spectral Library Version 1: 0.2 to 3.0 \%.im. Denver, USGS, Open File Report 93-592.

Clark R.N. \& Swayze G.A. 1995. Mapping minerals, amorphous materials, environmental materials, vegetation, water, ice and snow, and other materials: the USGS Tricorder Algorithm. In: Fifth Annual JPL Airborne Earth Science Workshop, JPL Publication 95-1,1:39-40.

Crosta A.P. \& Souza Filho C.R. de 1997. Evaluating AVIRIS hyperspectral remote sensing data for geological mapping in laterized terranes, Central Brazil. In: Twelfth International Conference on Applied Geologic Remote Sensing, Denver, Proceedings, 2: 430-437.

Crosta A. P., Sabine C., Taranik J.V. 1998. Hydrothermal alteration mapping at Bodie, California, using AVIRIS hyperspectral data. Remote Sensing of Environment, 65:309-319.

DNPM 1976. Carta Geológica do Brasil ao Milionésimo, Folha Brasília SD. 23.

Galvao L.S., Vitorello I., Almeida-Filho R. 1999. Effects of band positioning and bandwidth on NDVI measurements of tropical savannas. Remote Sensing of Environment, 67:181-193.
Green R.O., Conel J.E., Roberts D.A. 1993. Estimation of aerosol optical depth, pressure elevation, water vapor and calculation of apparent surface reflectance from radiance measured by the Airborne Visible/Infrared Imaging Spectrometer (AVIRIS) using a radiative transfer code. $\mathrm{SP} / £, 1937: 2-11$.

Green R.O., Conel J.E., Margolis J., Chovit C., Faust J. 1996. In-flight calibration and validation of the Airborne Visible/Infrared Imaging Spectrometer (AVIRIS). In: Sixth Annual JPL Airborne Earth Science Workshop, Pasadena, JPL Publ. 96-4,1:115126.

Prado D.M \& Crosta A.P. 1997. Evaluating Geoscan AMSS Mk-II for gold exploration in the Fazenda Maria Preta District, Rio Itapicuru Greenstone Belt, Bahia State, Brazil. Boletim IG-USP - Serie Cientifica, 28:63-84. 